\title{
APRESENTAÇÃO:
}

\section{A LITERATURA DE EXPRESSÃO ALEMÃ NO BRASIL E A LITERATURA BRASILEIRA EM ALEMÃO EM TRADUÇÃO}

Este número temático Troca de olhares se constitui tanto de estudos sobre versões já disponíveis, como de indagações concernentes a traduções em processo, e a edição pretende servir de guia a iminentes projetos de tradução situados entre as duas línguas. Uma coleção, portanto, mas em desalinho natural e avessa à pretensão de completude, de definitude! Reunindo a exigência acadêmica de exercício metodológico e sistemático ao desejo de fomentar diálogos entre os pares dedicados à pesquisa e à tradução literária no interstício proposto, a organização acontece no ínterim de confinamento físico e gradual aproximação social virtual, tendência nas atuais circunstâncias. As relações históricas e culturais entre os povos do idioma português-brasileiro e os do alemão têm uma contemporaneidade larga. Seria possível estendêla até Hans Staden, figura arquetípica dessa reciprocidade, uma vez que a imagem autêntica e histórica das cerimônias dos índios antropófagos, legada com o texto escrito e as ilustrações originais do seu relato sobre o Brasil de $1557^{1}$, se reverte simbolicamente durante o modernismo brasileiro ao princípio da antropofagia cultural. As passagens de povos germânicos pelas terras brasileiras tiveram acentos diversos; em certos casos, mais que incidentais ou episódicas, instauraram mudanças definitivas da natureza física e humana. O Barão de Eschwege empreendeu pesquisas geognósticas

BREMER, Georg. Die unerhörten Abenteuer der deutschen Konquistadoren Hans Staden und Ulrich Schmidel. Zürich: Schweizer Verl.-Haus, 1996. 
e topográficas, e das riquezas minerais brasileiras - diamante, ouro e outros ${ }^{2}$, o zoólogo Johann Baptiste von Spix e o botânico Martius Staden, autores de referências científicas canônicas, são exemplos do interesse europeu inicialmente voltado às formas naturais (solo, clima, fauna e flora) para posteriormente se conscientizar da literatura brasileira ${ }^{3}$. Sabe-se que Os sermões do Padre António Vieira (1608-1697) foram traduzidos em 1862 por Franz Joseph Schermer e há várias versões desde o decurso do século XIX, tanto do poema "A canção do exílio", de Gonçalves Dias, como também dos romances indianistas de José de Alencar para a língua alemã.

A partir de 1820, com a independência política e as correntes migratórias da Europa rumo ao Brasil, a tradução assume papel fundamental no convívio de povos de culturas diversas. No período entre 1933 e 1945, o Brasil acolheu um contingente expressivo de refugiados em decorrência das perseguições do nazismo, entre eles intelectuais ligados à literatura, às artes e à ciência. ${ }^{4}$

O fluxo de judeus, alemães, austríacos e de tantas outras origens, que tinham em comum a língua alemã e à terra brasilis imigraram, resultou em transformações culturais e contribuiu para expandir os horizontes literários brasileiros e aprimorar as metodologias de estudo, comparação, criação. Os entreolhares se invertem, quando agora os jovens poetas migrantes difundem a poesia brasileira em Luxemburgo, na Alemanha, na Suíça.

Os Estudos Culturais enfrentam há décadas as ideias de cânone e norte, extrapolam conceitos de origem e influência. Com isso, os Estudos Comparados (em especial a tradução) se tornam suscetíveis

2 ESCHWEGE. Pluto Brasiliensis. Collectanea de Scientistas Extrangeiros (assumptos mineiros). Tradução e anotações finaes de Rodolpho Jacob. Bello Horizonte: Imprensa Official de Minas Geraes, 1930.

3 ZILLY, Berthold. "Vorwort". In: KÜPPER, Klaus. Bibliographie der brasilianischen Literatur. Prosa, Lyrik und Drama in deutscher Übersetzung. Köln: Klaus Küpper/TFM, 2012. P. VII.

${ }^{4}$ Especificamente acerca do tema, em 2016 a TV Arte 1 apresentou a série Canto dos Exilados, produzida por Leonardo Dourado e Kristina Michahelles, com a participação de Alberto Dines, um documentário de biografias relevantes na formação da história cultural brasileira.

Cad. Trad., Florianópolis, v. 41, no 3 p. 12-17, set-dez, 2021. 
a operações depuradas, lapidares. A tradução é disciplina teórica relevante num país que encerra tantas línguas e diferenças. Ela auxilia nas relações pessoais, sociais, na superação de limitações interdisciplinares, ao estabelecer pontes e incrementar cada vez mais as disciplinas de Letras.

"Vorübergehen" "Passar" tange a temporalidade deste documento: um piscar de olhos, ein Augenblick. A moldura de Troca de Olhares, a composição que tem lado a lado o poema de August Stramm e a tradução de Augusto de Campos, reverencia o poeta que expandiu o repertório poético de língua portuguesa com suas criações intraduções transcriações.

O poema de Bertolt Brecht vertido ao português abre Troca de olhares e remete num lampejo à obra emblemática de enfrentamento ao autoritarismo. Essa arte-epígrafe deve ser o Leitmotiv de nossas aplicações: a conclamação à resistência por meio da Poesia.

O artigo "Traduzir: escrever entre línguas" do âmbito da filosofia da linguagem contrapõe tradições antigas e míticas a ramos de caráter empírico, com inferências instigantes para a pesquisa em tradução literária. Igualmente dentro de um escopo teórico, "Traduzir, Remontar" propõe a atividade da tradução poética como categoria de ordem marcadamente crítica, à semelhança das transcriações (propostas por Haroldo de Campos), nas quais entre a desmontagem e as remontagens a criação exerce papel preponderante.

"'Paris arde', de Ivan Goll: a metrópole desencantada" apresenta o poema modernista e expõe uma análise que visa a tradução poética. Recuperando estudos poéticos diacrônicos, o artigo "Tradução e História em Anatol Rosenfeld" cunha um registro documental do crítico berlinense que atuou nos estudos comparados alemão-português e vice-versa.

Três trabalhos representam tendências contemporâneas da literatura em prosa. Um deles se debruça sobre o romance Der vergessliche Riese de David Wagner, uma das várias obras da atualidade que têm como tema central o mal de Alzheimer. Os dois artigos seguintes são contribuições à teoria da tradução - 
"Traduzindo o sotaque de Tawada" lê a literatura em expressão alemã, o ensaio "Akzent", e analisa o estilo e a tradução para o português intitulada "Sotaque"; ao passo que "Traduzindo o Passado - Erinnern als Prozess des Übersetzens am Beispiel von Noemi Jaffes $O$ que os cegos estão sonhando" parte da obra literária brasileira para pensar a memória cultural da Shoah, abordando conceitos como recodificação, re-semiotização e realocação das memórias.

Na sequência, três artigos compõem uma série de estudos voltados à dramaturgia. "Maria Stuart de Schiller em tradução de Manuel Bandeira” acompanha os meandros da recepção desse trabalho que o poeta realizou para a encenação do Teatro Brasileiro de Comédia. "Ein Favela-Musical übersetzen: Vinícius de Moraes' Orfeu da Conceição auf Deutsch" investiga na tradução estratégias capazes de matizar as nuanças das variantes culturais. $\mathrm{O}$ artigo em torno de "Elfriede Jelinek no Brasil" pondera os objetivos desse projeto de tradução e a importância dessa dramaturgia ao debate estético contemporâneo.

A literatura de Kafka está presente neste volume através do artigo sobre "a retradução de Die Verwandlung de Kafka", partindo já do desconcerto a que predispõe o "monstruoso bicho repugnante".

Sobremaneira em três dos projetos, os debates da História e da Memória redimensionam a teoria da literatura, bem como os estudos da tradução. O artigo voltado às "Cartas de Resistência" do período da ditadura do nacional-socialismo leva em conta a aproximação entre as dimensões histórica e subjetiva. $\mathrm{O}$ artigo "Sete dias na Babilônia" se refere antes a questões abstratas das línguas e da linguagem humana que à personalidade do médico-escritor húngaro Lenard exilado no interior brasileiro. Por sua vez, "Textos silenciados e textos traduzidos", mais ainda se desprendendo da precisão temporal, analisa a literatura de expressão alemã escrita no Brasil e formula indagações sobre o sentir-se exilado.

Este número temático da revista Cadernos de Tradução não poderia passar ao largo da matéria estudos de Goethe no Brasil, em virtude de sua considerável tradição. Sob esse viés, uma das 
colaborações, de cunho evidentemente comparatista, entabula a discussão "Goethe além do nacional - conversações entre Leipzig e Bahia”. A extraordinária coleção de poemas do escritor, inspirada pelas leituras da poesia persa de Hafez, cuja versão ao português foi recentemente publicada, é objeto da resenha expandida "O Divã de Goethe no Brasil”. E a tradução de referência Fausto uma tragédia, realizada por Jenny Klabin Segall, é apreciada na investigação "E tudo fica melodia" sob a perspectiva da versificação e da musicalidade.

A recepção de "Meu tio o Iauaretê" (1961) de João Guimarães Rosa na versão em alemão de Curt Meyer-Clason, Mein Onkel der Jaguar (1981), concerne em “Jäger oder Jaguar - ambivalente Perspektivität und hybride Versprachlichung" às variantes morfológicas híbridas tupi-português, feito "jaguanhenhém”, e à perspectiva da oralidade narrativa diante de um leitor implícito.

$\mathrm{Na}$ reverberação de dois romances policiais marcantes que tinham sido à época traduzidos ao alemão (Agosto e Vastas emoções e pensamentos imperfeitos), o escritor Rubem Fonseca (19252020) esteve duas vezes na Alemanha nos anos 1990 e deixou um depoimento sobre suas experiências. Troca de olhares apresenta agora a tradução desse legado: "Erinnerungen an Berlin". Os organizadores deste número consistimos no exclusivo público de um bate-papo com o escritor na Alte Feuerwache Köln em 1994, quando da sua segunda estada naquele país, fato que desdobra a rememoração desse diálogo literário.

O ensaio "O Espaço mental de Baltasar Gracián: acerca da fascinação de uma concretude fria”, em sofisticada leitura e tradução brasileiras, quer aqui significar um exemplar 'espaço nômade do saber' (conforme Eneida Maria de Souza), em que as estéticas e os saberes se encontram em amplo intercâmbio. Rizoma, com ramificações sem estabelecimento local, tampouco analogia dual.

"Ein brasilianisches Gedicht ins Deutsche bringen" "levar um poema brasileiro ao alemão" é um projeto que envolve poetas brasileiros contemporâneos e equipes tradutoras. Esses poemas com as respectivas traduções identificam o que este número 
temático deseja sublinhar: a poesia em linguagem permeável e maleável às leituras.

"Toda ação que consiste na tendência de expandir o encadeamento palavra-pós-palavra me parece medonha e, tanto mais devastadora nos casos em que a relação irrestrita entre palavra e ato incorre, como agora entre nós cada vez mais, se consolida como um mecanismo para a realização de um fim absoluto."

Walter Benjamin (carta a Martin Buber, julho de 1916)

Werner L. Heidermann e Maria Aparecida Barbosa (organizadores) Universidade Federal de Santa Catarina, Florianópolis, Santa Catarina, Brasil 